\title{
OS MODELOS PLÁSTICOS AUXILIARES E A REALIZAÇÃO DE ESCORÇOS: DISPUTAS ENTRE CONHECIMENTO CIENTÍFICO E CONHECIMENTO EMPÍRICO
}

\author{
Alexandre Ragazzi \\ Doutorando em História da Arte - IFCH / UNICAMP \\ Bolsista FAPESP
}

Havia na Itália da segunda metade do século XVI alguns conceitos que já estavam a tal ponto sedimentados que não mais se discutia a seu respeito. Com efeito, eles formavam as bases a partir das quais novas disputas eram promovidas. Por exemplo, havia a convicção de que a pintura era técnica, isto é, de que se tratava de algo que podia ser aprendido; uma convicção que se estendia até a aceitação de que essa técnica deveria ser manuseada mesmo no caso dos possuidores de algum extraordinário talento natural. A polêmica daí decorrente, portanto, não mais se debruçava sobre uma oposição entre ingenium e inventio ${ }^{1}$ - em termos modernos, entre talento e empenho -, mas sim sobre a natureza da técnica a ser empregada.

\section{O confronto entre conhecimento científico e conhecimento empírico}

A fundação da Accademia del Disegno, em 1563, representa uma vontade coletiva de artistas que havia já algum tempo ambicionavam elevar sua própria posição social. Esses artistas não mais queriam ser confundidos com o simples artesão - com quem eram equiparados ao menos desde a Grécia antiga devido ao conceito compartilhado de téchne. Para tanto, eles precisaram assentir com uma crescente intelectualização da própria atividade. Um dado sintomático dessa época é o grande número de tratados sobre a pintura surgidos a partir de 15472 , sobretudo se se estabelecer uma comparação com a primeira metade do século, em que uma imensa lacuna sobre esse gênero se faz notar. A partir de então a teorização da perspectiva passou a ser matéria de interesse comum e muitas foram as tentativas de

\footnotetext{
1 Conceitos compreendidos conforme suas acepções da Antigüidade, ou seja, com a intenção de marcar a distinção entre o que é inato ou proveniente de um contato com algo supra-sensível e tudo aquilo que se pode alcançar por esforço próprio.

2 Data da publicação - por Lodovico Domenichi - da tradução para o italiano da obra sobre a pintura de Leon Battista Alberti.
} 
codificação e sistematização de suas regras ${ }^{3}$. Em alguns momentos, pode-se mesmo perceber algum descaso em relação aos artistas que abdicavam da teoria para se valer exclusivamente da prática e do olho.

Giovanni Paolo Lomazzo, em seu tratado de 1584, chegou a estabelecer três métodos através dos quais um artista poderia orientar-se para realizar o desenho de uma arquitetura em perspectiva ou de um corpo em escorço ${ }^{4}$. O primeiro fundamenta-se inteiramente na razão, na matemática; o segundo contenta-se com a prática; quanto ao terceiro, tratase de um processo intermediário, mecânico, que se vale da observação do modelo amparada pela utilização de instrumentos de transposição das medidas $^{5}$. Todavia, no que se refere ao segundo caminho, Lomazzo afirma ${ }^{6}$ :

A segunda parte se faz sem medida alguma, isto é, com o retratar e o imitar o natural ou ainda com o fazer de fantasia. Encontram-se mais pintores dessa espécie do que da outra [i.e., dos que se valem da razão]; e são mesmo tidos como talentosos porque se esforçam em imitar minuciosamente o natural, segundo o qual fazem algumas fantasias, mas em suas obras vêem-se grandes erros, os quais não cometem os conhecedores do conceito do ver e do operar.

Tem-se estabelecida, portanto, a distinção entre duas vertentes bastante evidentes e, em muitos casos, antagônicas, embora ambas constituam elementos pertencentes a uma mesma categoria - a técnica da pintura daquele período. Uma extrai seus fundamentos de um conhecimento que se pretende científico, a outra de um conhecimento empírico. De um lado está a epistéme, de outro a empeiría.

Antes desse notável embate que se pode constatar em Lomazzo havia, em meio aos artistas ativos durante a primeira metade do Quinhentos - que de certa forma eram continuadores do ideal de união entre ciência e arte almejado já desde os primeiros humanistas -, como que um equilíbrio entre as duas possibilidades. Os conhecimentos científicos eram assimilados e então aliados à experiência. O interesse que Leonardo da Vinci mantinha pela ciência decerto não o impediu de também utilizar modelos plásticos

3 Cf., entre outros, os tratados de Daniele Barbaro (1569) e Jean Cousin (1560, 1571), a polêmica suscitada por Martino Bassi (1572), a tradução de Euclides realizada por Egnazio Danti (1573), o comentário feito por este a Vignola (1583) e a obra de Sirigatti (1593).

4 Cf. LOMAZZO, Gio. Paolo, Trattato dell'arte della pittura, Diviso in sette libri, Ne' quali si contiene tutta la theorica e la prattica d'essa pittura. Milano: Paolo Gottardo Pontio, 1584, pp. 275-7. Segundo Lomazzo, essa distinção estaria presente no tratado - perdido - sobre a perspectiva de Bramantino.

5 Cf. LOMAZZO, 1584, pp. 317-21.

6 LOMAZZO, 1584, p. 276. Salvo outra indicação, as traduções dos trechos doravante citados são de nossa autoria. 
auxiliares $^{7}$ - e não há incoerência alguma nessa constatação. Entretanto, para os artistas da geração de Lomazzo as coisas não se davam dessa maneira. Despontava alguma inquietação, e de harmônico o ambiente passou a instável. Isso pode ser comprovado em um relato tardio de um dos seguidores de Giulio Romano em que está presente tanto uma comprovação emblemática da interação desses dois métodos quanto uma tendência rumo a uma ruptura que se anunciava para, em breve, ser perpetrada.

\section{O método de Giulio Romano}

Em 1580 o pintor veronês Cristoforo Sorte ${ }^{8}$ indicava dois métodos possíveis para se reproduzir uma arquitetura em perspectiva ou um corpo em escorço. O primeiro insistia na utilização dos conhecidos pontos principal e de distância - com a ressalva de que este deveria ser rebaixado. $\mathrm{O}$ segundo, completamente fundamentado na prática, recomendava a utilização de um espelho ao qual se deveria sobrepor um modelo plástico substituinte do objeto a ser reproduzido. De acordo com Sorte, esses caminhos teriam sido ensinados a ele, em Mântua, por Giulio Romano. Ele diz ${ }^{9}$

Quando me exercitava com Giulio Romano - o qual era pródigo em belíssimas invenções, tanto em pintura e arquitetura quanto em perspectivas de planos e escorços -, ele me mostrou dois modos para conduzir a [galeria com colunas, balaústres e teto ${ }^{10}$. O primeiro considera dois pontos, um dos quais deveria ser colocado no meio do espaço - que é o ponto para o qual convergem as linhas -, enquanto que o

7 Cf. VINCI, Leonardo da, Libro di pittura - Edizione in facsimile del Codice Urbinate Lat. 1270 nella Biblioteca Apostolica Vaticana, Firenze: Giunti, 1995, p. 175. GIOVIO, Paolo, Leonardo Vincii vita; Michaelis Angeli vita; Raphaëlis Urbinatis vita; fragmentum trium diagororum, in: BAROCCHI, Paola (org.), Scritti d'arte del Cinquecento, I, Milano, Napoli: Riccardo Ricciardi, 1971, p. 7. VASARI, Giorgio, Le vite de' più eccellenti pittori, scultori e architettori: con i ritratti loro et con l'aggiunta delle vite de' vivi e de' morti dall'anno 1550 insino al 1567, Firenze: Giunti, 1568, IV, p. 17 (edição consultada através do projeto Signum do Centro di ricerche informatiche per le discipline umanistiche da Scuola Normale Superiore di Pisa, endereço eletrônico biblio.signum.sns.it/vasari/consultazione/Vasari/indice.html (consultado em 14/01/2009), o qual está alinhado com os volumes e a paginação de VASARI, Giorgio, Le vite de' più eccellenti... nelle redazioni del 1550 e 1568, testo a cura di Rosanna Bettarini, commento secolare a cura di Paola Barocchi, 6v., Firenze: Sansoni / S.P.E.S, 1966-1987). KWAKKELSTEIN, Michael W., The use of sculptural models by Italian Renaissance painters: Leonardo da Vinci's 'Madonna of the rocks' reconsidered in light of his working procedures, in: Gazette des Beaux-Arts, n. 1563, 1999, pp. 181-198.

8 SORTE, Christoforo, Osservationi nella pittura - Con l'aggionta d'una cronichetta dell'origine della magnifica città di Verona, Venetia: Gio. Ant. Rampazetto, 1594 (1580).

9 SORTE, 1594, f. 20r-v.

${ }^{10}$ Encomenda que Sorte recebera de Federico Gonzaga para o Palaz̨o Ducale de Mântua. Essa obra não foi conservada. 
outro seria disposto abaixo do horizonte ${ }^{11}$. Isso deveria ser feito do mesmo modo que se observou na perspectiva do plano há pouco demonstrada ${ }^{12}$ - seja no que se refere ao ponto para o qual convergem as linhas, seja quanto ao ponto disposto abaixo do horizonte. $\mathrm{O}$ outro modo consiste em um espelho sobre o qual se entrelaça, em uma moldura, uma quadrícula com a mesma dimensão do espelho. Essa quadrícula deve ser feita com uma linha ou com fios de seda preta, dividida em tantos quadrados quantos se quiser. Em seguida, ela deve ser disposta sobre o espelho, muito bem fixada. E querendo-se imitar no teto colunas, figuras ou outra coisa em escorço, deve-se fazer, primeiramente, o objeto que se quer pintar em relevo, isto é, deve-se fazer um modelo. Este deve ser colocado à altura adequada, à distância que deve ser representado, com a iluminação conveniente para que se possam ver a incidência das sombras e os relevos nos seus devidos lugares. E o mencionado espelho, sobreposto pela quadrícula, deve ser colocado embaixo [do modelo], no meio da sala ou lugar em que se há de pintar. É preciso garantir que o espelho seja o horizonte, mas que fique acomodado de tal modo que o reflexo de tudo que se há de imitar possa ser visto. Feito isso, é necessário que o pintor se instale adequadamente, com o olhar fixo, com um papel quadriculado em mãos, até que tenha delineado o que vê no espelho, insistindo nas sombras, nas esfumaturas e nas luzes com os seus reflexos apropriados. Se o que foi dito for seguido, sem nenhuma resistência há de se ver a obra alcançar sucesso, como prova a seguinte figura ${ }^{13}$.

Essa singular descrição deixa claro que os dois métodos eram reconhecidos. Entretanto, nos momentos da realização da obra parece que a segunda via de algum modo era preferida - naturalmente que sem a necessidade do peculiar auxílio do espelho proposto por Giulio Romano. Com efeito, essa situação tende a ser verdadeira ao menos até os artistas pertencentes às gerações que têm seu fim junto com o século. Mas como mudanças na prática artística não ocorrem subitamente - porquanto são indícios de processos de transformação do pensamento -, durante a segunda metade do século XVI encontram-se tanto aqueles que defendem quanto aqueles que desaprovam a utilização de modelos plásticos auxiliares. Portanto, não deve causar perplexidade a constatação de que Lomazzo, por várias vezes, pareça hesitar entre as duas possibilidades. Por exemplo, após

${ }^{11}$ Método fundamentado na projeção geométrica e que se vale do ponto principal - conhecido também como ponto de horizonte ou de perspectiva (cf. VIGNOLA-DANTI, Le due regole della prospettiva pratica di M. Iacomo Barozzi da Vignola - Con i comentarii del R. P. M. Egnatio Danti... Roma: Francesco Zannetti, 1583, pp. 4-6) - e do ponto de distância, o qual, nesse caso, deveria ser rebaixado para que fosse criada a ilusão de um escorço mais acentuado. Efetivamente, o resultado corresponde ao afastamento do ponto de distância.

${ }^{12}$ Sorte faz alusão ao f. $19 \mathrm{v}$, em que expõe o método tradicional - com ponto principal e ponto de distância - para a projeção em perspectiva.

${ }^{13}$ Sorte faz referência a um desenho impresso ao f. $21 \mathrm{r}$, o qual representa, em escorço, uma coluna de relevos bastante salientes. Esse desenho não consta na edição de 1580. Barocchi (Trattati d'arte del Cinquecento - Fra manierismo e Controriforma, 3 v., Bari: Gius. Laterza, 1960-2, I, pp. 271-301, 526-39), que não conseguiu consultar a edição de 1594, procurou suprir essa lacuna com um desenho que representa uma arquitetura sendo projetada em um espelho (nossa fig. 1). Embora esse desenho proposto por Barocchi não tenha relação com o que foi inserido na edição de 1594, seguramente ilustra com muito maior precisão o método de Giulio Romano. 
a descrição de um aparato mecânico recomendado por ele para a transposição de um modelo escultórico para o desenho - o método intermediário segundo sua própria concepção, aquele que alia teoria e prática -, ele afirma que as figuras oblíquas e inclinadas podem ser feitas com esse método, ainda que seja algo muito difícil e trabalhoso, pelo que é melhor fazệ-las (...) com o auxílio de figuras de madeira, argila e cera e seus devidos tecidos e luzes ${ }^{14}$.

A utilização de modelos plásticos auxiliares, como se sabe ${ }^{15}$, era prática comum ao menos desde Piero della Francesca ${ }^{16}$. Todavia, a expressão máxima dessa prática parece ter sido alcançada entre os artistas da Itália setentrional, os quais se valiam da mesma não apenas para resolver problemas inerentes ao panejamento e ao desenho, mas ainda para solucionar questões decorrentes de escorços muito acentuados ${ }^{17}$ e de efeitos de luz e sombra. A descrição mais surpreendente de utilização de tal prática foi feita por Carlo Ridolfi, que apresenta, sem que haja motivos para se duvidar de seu relato, o método de trabalho adotado por Tintoretto ${ }^{18}$ :

[Tintoretto] também se exercitava fazendo pequenos modelos de cera e argila, vestindo-os com panos, procurando minuciosamente através das pregas dos tecidos as formas dos membros. Depois distribuía [esses modelos] em pequenas casas e perspectivas feitas com tábuas e cartões, ajustando, pelas janelas, pequenas tochas, extraindo de tal modo as luzes e as sombras. Também suspendia com fios alguns

${ }^{14}$ LOMAZZO, 1584, p. 321. A questão ganha em Lomazzo um componente adicional porque o autor freqüentemente se mostra empenhado em dar sua contribuição - ainda que de modo espontâneo e tardio - acerca do paragone entre a pintura e a escultura. Lomazzo chega a citar a disputa promovida por Varchi (cf. LOMAZZO, 1584, p. 331) e, na ânsia de libertar a pintura da escultura, ele afirma: $A$ arte da estatuária, da plástica ou, se se preferir, a arte do fazer figuras em relevo - a qual tem muita familiaridade com a pintura por adicionar e subtrair com discernimento - teve origem muitissimos anos antes da arte da escultura, com a qual são entalhados os mármores e outros materiais semelhantes. Por isso, pode ser considerada, com razãa, mãe da escultura e irmã da pintura (LOMAZZO, 1584, p. 328 [cf. 1584, p. 253]). Portanto, para ele, se em algum momento a pintura precisar utilizar modelos plásticos auxiliares (cf. LOMAZZO, Gio. Paolo, Idea del tempio della pittura, Milano: Paolo Gottardo Pontio, 1590, pp. 36, 53), que fique claro que esses são elementos procedentes da plástica, não da escultura. Essa é a razão que lhe permite ora afirmar que o pintor Michelangelo jamais utilizou modelos plásticos auxiliares (cf. LOMAZZO, 1584, p. 252) e ora dizer justamente o contrário (cf. LOMAZZO, 1590, p. 36). Sobre a intenção de Lomazzo de que o Trattato e Idea compusessem um livro único, cf. ACKERMAN, Gerald M., Lomazzo's treatise on painting, in: The Art Bulletin, v. 49, n. 4, 1967, pp. 317-326.

${ }^{15}$ Cf. RAGAZZI, Alexandre, A tradição da pintura que tem como modelo a escultura, in: Daumier escultor: correspondências com a pintura e a obra gráfica, Dissertação de Mestrado, Orientação de Luciano Migliaccio, Campinas, SP: [s.n.], 2004, pp. 03-24; 35-7.

${ }^{16}$ Cf. VASARI, 1568, III, p. 264.

17 Interessante, a esse respeito, a opinião de Lomazzo quanto à predisposição dos artistas do norte para obras com perspectivas mais radicais: (...) assim como afirmam os antigos e os modernos perspectivos, máxime os lombardos, aos quais essa parte é própria do mesmo modo que o desenho é peculiar aos romanos, a cor aos venezianos e as bizarras criações aos germânicos (LOMAZZO, 1584, p. 317).

${ }^{18}$ RIDOLFI, Carlo. Delle maraviglie dell'arte, overo delle vite degl'illustri pittori Veneti e dello Stato, Venetia: Gio. Battista Sgava, 1648, II, pp. 6-7. 
modelos nas vigas para observar os efeitos que produziam quando vistos de baixo, para [assim] formar os escorços que se pintam nos tetos, compondo de tal modo estranhas invenções ${ }^{19}$.

As possibilidades que se apresentavam ao artista por meio dessa técnica, os resultados que se poderiam alcançar, tudo é levado a um grau máximo em Tintoretto, pintor de luz, de sombra, de escorços audazes, de anjos que flutuam no ar. Entretanto, ao mesmo tempo em que alguns avançam as experimentações, outros condenam veementemente a prática sobretudo os que queriam fazer da pintura uma arte rigorosamente científica. Esse é o caso de Carlo Urbino da Crema, artista e teórico que aderiu à tradição de Leonardo com toda a ortodoxia possivel ${ }^{20}$. No fólio $111 \mathrm{r}-\mathrm{v}$ das Regras do desenho, Carlo Urbino apresenta suas teorias sobre a representação dos corpos que deveriam ser vistos de baixo para cima e suspensos no $\operatorname{ar}^{21}$ :

Mas são mais difíceis aqueles ${ }^{22}$ que são feitos por entre as nuvens e soltos no ar, de acordo com a vontade do pintor, como que voando sem qualquer parâmetro de distância, pois que [nesse caso] o pintor não é orientado por uma posição real ou estável conhecida quanto à altura e à distância. Todavia acreditavam e ainda acreditam alguns ótimos pintores - que desejam alcançar tal arte no formar os corpos - que a prática do retratar pequenos e bem acabados modelos de madeira, estuque, cera ou argila constitui a verdadeira arte da qual pode se servir o pintor para imitar os objetos. Sem consideração pela verdadeira ciência - na qual está depositado o todo das demonstrações que até aqui fizemos [acreditam que possam] extrair desses modelos o desenho de acordo com o movimento e o ponto de vista e depois transferi-lo, em tamanho adequado, segundo deva ser realizado em parede ou tela.

Adiante, no fólio $112 \mathrm{v}$, após a seqüência de críticas e admoestações aos que não conseguem operar sem o auxílio dos modelos plásticos, Urbino declara com uma certa condescendência: (...) e isso como advertência àqueles que se servem dos modelinhos, para não os privar deles, uma vez que são o auxílio daqueles que são desprovidos da parte mais nobre em que a nossa arte vai buscar a nobreza $a^{23}$.

${ }_{19}$ Ao que parece, essa passagem de Ridolfi serviu de fonte para LANZI, Luigi, Storia pittorica della Italia Dal risorgimento delle belle arti fin presso al fine del XVIII secolo, II, Firenze: Sansoni, 1970 (1795-6), p. 88. Este, por sua vez, foi retomado por SELVATICO, P., Storia estetico-critica delle arti del disegno, II, Venezia: Pietro Naratovich, 1856, pp. 564-5.

${ }^{20}$ Cf. PANOFSKY, Erwin, Le Codex Huygens et la théorie de l'art de Léonard de Vinci, trad. Daniel Arasse, Paris: Flammarion, 1996 (1940), p. 62.

${ }^{21}$ URBINO DA CREMA, Carlo, Le regole del disegno, In: PANOFSKY, 1996, p. 54, nota 153. Quanto à atribuição do Codex Huygens a Carlo Urbino, cf. MARINELLI, Sergio, The Author of the Codex Huygens, in: Journal of the Warburg and Courtauld Institutes, v. 44, 1981, pp. 214-220.

22 As representações de corpos dispostos acima da altura dos olhos do pintor; mais difíceis se comparados aos corpos apoiados sobre algum plano elevado.

${ }^{23}$ Todavia, deve-se notar que Marinelli (1981, pp. 219-20), com bastante razão, apontou para o fato de que Carlo Urbino, apesar de seu discurso, provavelmente também recorria aos modelos plásticos auxiliares. Mas deixemos isso para outra ocasião. 
Dados esses exemplos, é preciso então ter claro que nesse ambiente a controvérsia a respeito da utilização de modelos plásticos para a pintura se mostrava cada vez mais explícita. De um lado havia a grande maioria, os continuadores da tradição ${ }^{24}$; de outro, a crescente valorização da intelectualização da atividade artística e a expansão de um conceito de origem clássica que havia já algum tempo se estabelecera firmemente - a noção de idéia.

\section{As orientações de Federico Zuccaro}

Quando Cícero, no Orador, transferiu o conceito platônico de idéia de um mundo metafísico para a própria mente do homem ele rompeu, a um só tempo, tanto com a crença de que o artista não era mais do que um instrumento de contato entre o mundo das essências e o mundo sensível quanto com o conceito de imitação como mera cópia da realidade. Ele diz:

Penso que não existe em parte alguma algo de tão belo cujo original de que foi copiado não seja ainda mais belo, como é o caso de um rosto em relação a seu retrato; mas não podemos apreender esse novo objeto nem pela visão, nem pela audição ou qualquer dos outros sentidos; ao contrário, é apenas em espírito e em pensamento que o conhecemos ${ }^{25}$.

Desse modo, Cícero excedia os limites da imitação estrita da natureza e, de certa forma, tornava acessível ao homem o mundo suprasensível. De fato, essa passagem cristalizava aspectos inerentes à criação artística do mundo antigo ${ }^{26}$, e o homem do Renascimento, que buscou intensamente fontes da Antigüidade para a constituição de sua própria identidade, não tardou a se dar conta das possibilidades que se the apresentavam. Coexistiam nesse ambiente, por conseguinte, as doutrinas neoplatônicas estimuladas por Ficino e Landino - prontamente adaptadas

${ }^{24}$ Entre muitos que poderíamos citar, cf. ARMENINI, Giovan Battista, De' veri precetti della pittura, Ravena: Francesco Tebaldini, 1587, pp. 6, 59, 86-7, 91, 93-4, 96-9, 100, 103, 138, 155-6, 223-5; е o Parecer sobre a pintura de Bernardino Campi, in: LAMO, Alessandro, Discorso di Alessandro Lamo intorno alla scoltura et pittura: dove ragiona della vita e opere in molti luoghi e a diverse prencipi e personaggi fatte dall'eccell. e nobile M. Bernardino Campo, pittore cremonese, Cremona: Christoforo Draconi, 1584, pp. 121-9.

25 Orator ad Brutum, II, 8 (trad. de Paulo Neves). A obra de Panofsky permanece fundamental para uma visão mais ampla a respeito das transformações desse conceito (PANOFSKY, Erwin, Idea: a evolução do conceito de belo, trad. Paulo Neves, São Paulo: Martins fontes, 2000 (1924)).

${ }^{26}$ Para uma discussão profunda acerca dos métodos de criação durante a Antigüidade, veja-se CICU, Luciano, Le api il miele la poesia - Dialettica intertestuale e sistema letterario greco-latino, Roma: Casa Editrice Università La Sapienza, 2005, obra que me foi gentilmente recomendada pelo professor Paulo Sérgio de Vasconcellos. 
ao modelo católico - e a crença de que a arte era imitação da realidade sendo que para satisfazer a ânsia por precisão científica característica do Renascimento essa imitação precisou ser largamente intermediada pela razão.

$\mathrm{Na}$ célebre carta endereçada a Castiglione, Rafael diz: para pintar uma bela mulher en precisaria ver várias mulheres belas, mas, por falta de belas mulberes, eu me sirvo de uma certa Idéia que me vem à mente ${ }^{27}$. No primeiro trecho da afirmação está contida e como que ecoa na mente do leitor a passagem das cinco virgens de Crotona ${ }^{28}$. Nesse caso, a obra seria elaborada a partir da diversidade existente na natureza. Quanto à alusão a essa certa idéia que vem à mente, ela poderia ser interpretada em termos platônicos, mas por se tratar de Rafael - o artista que soube extrair o melhor de tudo o que viu - é mais plausível que se trate de uma idéia formada não apenas a partir de cinco, mas de todas as belas mulheres já vistas pelo artista. Naturalmente que esse era considerado um caminho audacioso e realizável somente por poucos, porquanto a observação competente e paciente da natureza é uma via árdua, trabalhosa e lenta. Para a maioria, no entanto, mais proveitoso e efetivo seria a imitação de um grande artista, pois que, nas palavras de Giulio Camillo, aquele que imita um perfeito imita a perfeição de mil reunida em um ${ }^{29}$. Portanto, a maioria deveria se contentar com o caminho mais fácil, isto é, deveria aliar uma parcimoniosa imitação da natureza sobremodo valorizada se, de alguma forma, fosse amparada pela razão - ao auxílio suscitado pelos grandes artistas, justamente aqueles que conseguiram reunir em sua obra o melhor - seja porque observaram minuciosamente a natureza, seja porque sustentaram algum contato de origem supra-sensível.

Cristoforo Sorte, logo após descrever o método de Giulio Romano que há pouco relatamos, continua sua argumentação com o elogio dos pintores Cristoforo e Stefano de' Rossi (Rosa), os quais, segundo ele, possuíam os fundamentos da perspectiva em escorço, capacidade de

\footnotetext{
${ }^{27}$ Extraído de BELLORI, Giovan Pietro, L'Idea del pittore, dello scultore e dell'architetto scelta dalle bellezze naturali superiore alla natura - Discorso di Gio. Pietro Bellori detto nell'Accademia romana di San Luca la terza domenica di maggio MDCLXIV essendo principe dell'Accademia il Signor Carlo Maratti, in: MENGS, Anton R. Pensieri sulla bellezza, Milano: Alessandro Minuziano, 1948 (1672), p. 143.

${ }^{28}$ Cf., entre outros, CÍCERO, De Inventione, II, 1, 3 e PLÍNIO, Nat. hist., XXXV, 64.

${ }^{29}$ CAMILLO, Giulio, Due trattati dell'eccellentissimo M. Iulio Camillo: l'uno delle materie, che possono venir sotto lo stile dell'eloquente: l'altro della imitatione, Venetia: Farri, 1544, p. 40b. Embora esse tratado sobre a imitação tenha sido publicado apenas em 1544, ele deve ser integrado ao conjunto das reações desencadeadas a partir do Ciceronianus de Erasmo (1528).
} 
discernimento e inclinação natura ${ }^{30}$. Trata-se, com efeito, da união de ciência, prática e habilidade natural ${ }^{31}$. Entretanto, Sorte afirma que a fama desses artistas - e, por extensão, de todos os que quiseram, em qualquer profissão, alcançar a fama - não decorre simplesmente desses princípios, mas sobretudo de uma inclinação natural proveniente de influxos celestes. Ele ainda denomina essa inclinação de Idéia natural ou ensinamento celeste, o qual, infundido no homem a partir dos corpos superiores (...), não apenas ajuda a operar, mas nas maiores e mais perfeitas obras predomina com autoridade 32 . Portanto, é uma idéia constituída a priori e sobreposta aos métodos científicos e empíricos acima descritos.

Federico Zuccaro, por sua vez, preparou um programa de ensino para a Accademia di San Luca cuja importância deve ser potencializada por ter influenciado a Académie Royale de Peinture et de Sculpture, instituição que viria a se converter em modelo para diversas outras academias espalhadas pelo continente europeu. Em seus preceitos, Zuccaro não deixa de insistir em uma formação cujo programa apresenta inúmeras afinidades com a educação que os jovens artistas recebiam nos ateliês dos mestres. Ele assim determina as atribuições do instrutor encarregado das atividades ${ }^{33}$ :

Começará então a indicar aos estudantes o que devem fazer, a um isso e a outro aquilo, de acordo com suas aptidões, ou seja, deverá indicar quem desenhará a mão livre e quem fará cartões, relevos, cabeças, pés, mãos, quem durante a semana desenhará a partir do antigo, das fachadas de Polidoro, quem retratará perspectivas de vilarejos e de edifícios, quem fará animais e outras coisas do gênero. Além disso, na estação propícia, fará com que retratem nus, com graça e inteligência, e fará com que vistam e retratem, com boa maneira, modelos de argila e de cera.

Todavia, esse era apenas o primeiro estágio do programa. Uma vez dominada a técnica o pintor deveria então se orientar pela idéia, pelo que Zuccaro denomina como disegno interno ${ }^{34}$. Mas embora somente sistematizado por Zuccaro, há algum tempo esse programa já estava instaurado na cultura italiana - naturalmente que não sem provocar polêmicas $^{35}$. Por exemplo, essas orientações potencialmente já se faziam

${ }^{30}$ Cf. SORTE, 1594, f. 21v.

${ }^{31}$ Cf. PLATÃO, República, 374b-e.

32 Cf. SORTE, 1594, f. 21v.

33 ZUCCARI, Federico, ALBERTI, Romano, Origine, et progresso dell'Academia del Dissegno, de' Pittori, Scultori, e Architetti di Roma, Pavia: Pietro Bartoli, 1604, in: SCRITTI d'arte di Federico Zuccaro, Firenze: Leo S. Olschki, 1961, p. 20.

${ }^{34}$ ZUCCARO, Federico. L'Idea de' Pittori, Scultori, et Architetti, del Cavalier Federico Zuccaro, Torino: Agostino Disserolio, 1607. in: SCRITTI d'arte di Federico Zuccaro, Firenze: Leo S. Olschki, 1961, p. 152.

${ }^{35}$ Cf. ARMENINI, 1587, pp. 223-4. 
sentir na obra de Romano Alberti - futuro aliado literário do próprio Zuccaro -, para quem o pintor deveria ter os sentidos agucados e muito boa imaginação, com a qual [ele deveria] apreender as coisas dispostas diante dos olhos, [e estas], afastadas e transformadas em fantasmas, [deveriam então ser] perfeitamente submetidas ao intelecto ${ }^{36}$. Como é possível notar, o mundo sensível deveria ser apreendido pela imaginação e esta deveria então se apresentar como modelo para a obra que seria realizada - substituindo, assim, natureza ou modelos plásticos auxiliares.

Portanto, é na articulação de todos esses conceitos - conhecimento científico, conhecimento empírico e idéia - que está o centro das controvérsias acerca do emprego ou não de modelos de argila ou cera como aparato acessório para a pintura. Conforme afirmamos, despontava nesse ambiente algum menosprezo em relação aos artistas que rejeitavam uma postura mais intelectualizada em favor de uma prática exclusivamente amparada pela experiência. Somadas a esse fato, a intensificação do conceito de idéia e a ruptura com aristotelismo maneirista ${ }^{37}$ só fizeram aumentar a distância entre a utilização de modelos plásticos auxiliares e a execução da obra de $\operatorname{arte}^{38}$.

${ }^{36}$ ALBERTI, Romano. Trattato della nobiltà della pittura, Composto ad instantia della venerabil Compagnia di S. Luca, et nobil Academia delli pittori di Roma, Roma: Francesco Zannetti, 1585, p. 16.

${ }^{37}$ Cf. KLEIN, Robert, A forma e o inteligivel (1958), in: A forma e o inteligivel - Escritos sobre o Renascimento e a arte moderna, trad. Cely Arena. São Paulo: Edusp, 1998 (1970).

${ }^{38}$ Entre outros, resistiram a essa ruptura ao menos Poussin (cf. BELLORI, Giovan Pietro, Le vite de' pittori, scultori e architetti moderni, Torino: Giulio Einaudi, 1976 (1672), pp. 452-3) e Roger de Piles (cf. DU FRESNOY, Charles Alphonse, L'art de peinture, Paris: Nicolas L'Anglois, 1668, pp. 22-3, 109-11). Mas o rigor e a austeridade do primeiro e a atitude oposicionista do segundo face à Academia Francesa ajudam a compreender melhor suas posturas. Esperamos, no entanto, encontrar repostas mais satisfatórias com a pesquisa que atualmente está em curso. 


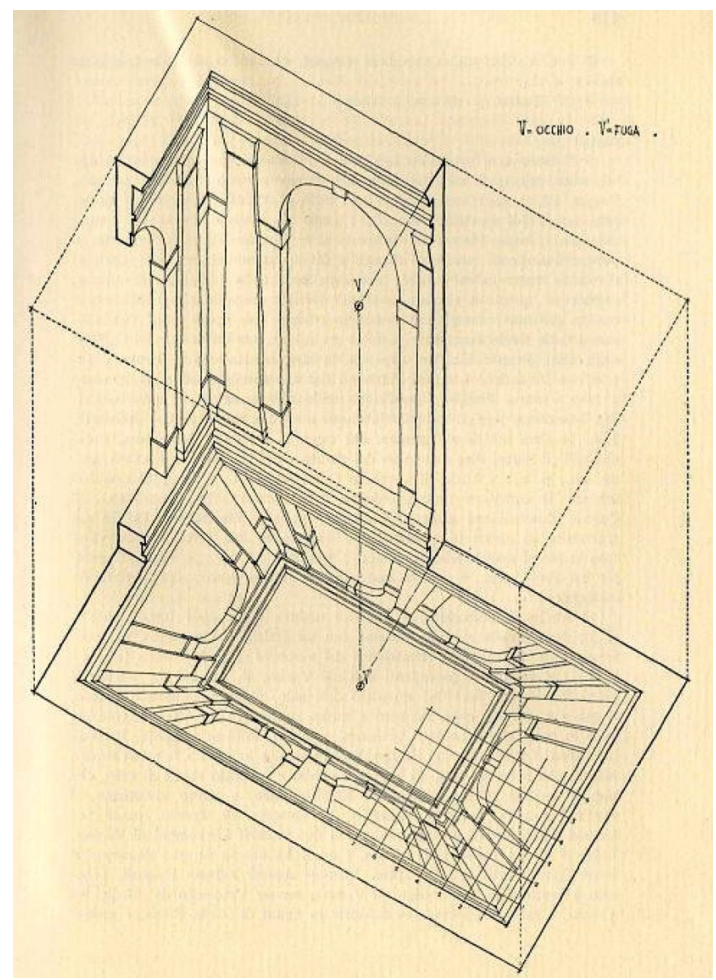

Fig. 1 - cf. nota 13

Reproduzida a partir da edição de Paola Barocchi 